\title{
A INTERAÇÃO ATRAVÉS DA INFORMÁTICA NA EDUCAÇÃO COM CRIANÇAS COM FIBROSE CÍSTICA E A INCLUSÃO SOCIAL E DIGITAL ATRAVÉS DO USO DA LEITURA E DA ESCRITA: UM ESTUDO DE CASO NOS ISOLAMENTOS DA PEDIATRIA DO HCPA
}

\author{
Eliane Lourdes da Silva Moro ${ }^{1}$ \\ Fernando Antonio de Abreu e Silva ${ }^{2}$ \\ Lizandra Brasil Estabel ${ }^{3}$ \\ Lucila Costi Santarosa ${ }^{4}$
}

Resumo: Este artigo apresenta uma atividade desenvolvida na área de informática na educação tendo como sujeitos duas Pessoas com Necessidades Educacionais Especiais (PNEEs), pacientes hospitalizadas no Hospital de Clínicas de Porto Alegre (HCPA), internadas em quartos restritos, realizando a terapêutica em isolamento total. Os sujeitos dessa experiência estão na faixa etária entre 10 e 12 anos, sendo uma paciente de fibrose cística e a outra transplantada com problemas crônicos. No processo de inclusão digital e de inclusão social as TICs (Tecnologias da Informação e da Comunicação), podem ser utilizadas pelas PNEEs, propiciando a comunicação, a expressão, a interação e o compartilhamento, através da linguagem oral e escrita, utilizando como mediação as ferramentas tecnológicas.

Palavras-chave: Pessoas com Necessidades Educacionais Especiais; Tecnologias de Informação e de Comunicação; crianças hospitalizadas.

Abstract. This paper presents an activity developed in the computer science field applied on the education having as subjects two Pessoas com Necessidades Educacionais Especiais (PNEEs), patients hospitalized in Hospital de Clínicas de Porto Alegre (HCPA), interned at restricted rooms, accomplishing the therapeutics in total isolation. The subject of this experience are in the age group between 10 and 12 years, one being a cystic fibrosis patient and the other transplanted with chronic problems. In the process of digital inclusion and of social inclusion the Technologies of the Information and Communication (TICs) can be used by PNEEs, allowing communication, expression, interaction and sharing, through the oral language and writing, using as mediators technological tools.

KEYWORDS: People with SpecialEducation Needs ; Information and Communication Technologies; hospitalized children.

\footnotetext{
${ }^{1}$ Professora do Curso de Biblioteconomia da FABICO/UFRGS, Especialista em Informática na Educação PGIE/UFRGS, Aluna do Programa de Pós-Graduação em Educação da UFRGS - PPGEdu/UFRGS, Coordenadora do Núcleo da Hora do Conto do DCI/FABICO/UFRGS. E-mail: mmoro@adufrgs.ufrgs.br ou eliane_moro@yahoo.com.br.

${ }^{2}$ Pós-Doutorado em Medicina in The Royal Hospital For Sick Children. Professor Adjunto na Faculdade de Medicina da UFRGS, com atuação profissional na Clínica Médica e Pneumologia. Vários artigos publicados em periódicos científicos. E-mail: dpp@vortex.ufrgs.br

${ }^{3}$ Professora do Curso de Biblioteconomia da FABICO/UFRGS, Especialista em Informática na Educação PGIE/UFRGS, Aluna do Doutorado de Informática na Educação - PGIE/UFRGS, Bibliotecária do Colégio Mãe de Deus e do Instituto Santa Luzia. E-mail:estabel@cpovo.net .

${ }^{4}$ Professora Doutora do PPGEDU e do PGIE/UFRGS, Coordenadora Nacional da RIBIE, Coordenadora de pesquisa do NIEE-UFRGS, E-mail: lucila.santarosa@ufrgs.br

V. $3 \mathrm{~N}^{\circ} 1$, Maio, 2005
} 


\section{INTRODUÇÃO}

Recentemente, e com relativa freqüência, autores, pesquisadores e professores vêm demonstrando em estudos que as diferenças são mais comuns que as similaridades, que ritmos, estilos e expressões são distintos e pertencem à individualidade de pessoas, e que são expressos por meio de suas experiências, vivências sociais, emocionais e cognitivas.

As Tecnologias de Informação e de Comunicação (TICs) exercem um papel fundamental como instrumentos de mediação entre os sujeitos em uma sociedade onde o acesso à informação é considerado um direito de todos os cidadãos. As TICs envolvem sujeitos sem nenhuma limitação de uso de suas ferramentas bibliográficas e eletrônicas e também Pessoas com Necessidades Especiais (PNEs) com limitação visual, auditiva, física, mental, incluindo entre outros, os doentes crônicos, através das Tecnologias Adaptativas ou Assistivas (TAs).

As TICs, aplicadas à Educação Especial, auxiliam as Pessoas com Necessidades Educacionais Especiais (PNEEs) através das TAs utilizando hardware, programas e ambiente que propiciem o acesso à informação, à comunicação, ao compartilhamento e à cooperação, favorecendo a conquista de novos paradigmas na área educacional e a realização de múltiplas vivências através da interação entre sujeitos, no processo de aprendizagem e na construção de novos conhecimentos, em Ambientes de Aprendizagem Mediados por Computador (AAMC). No AAMC o educador assume o papel de mediador, possibilitando aos educandos "o exercício da colaboração e da cooperação das atividades realizadas, com a participação ativa das situações de aprendizagem propostas, transformando o espaço de sala de aula em um ambiente efetivo de aprendizagem" (ESTABEL;MORO,2004)* e, ao mesmo tempo, efetivando o processo de inclusão digital e de inclusão social das PNEEs.

Dentre os doentes crônicos, considerados PNEEs, encontram-se as crianças com diagnóstico de fibrose cística. A Informática na Educação pode propiciar o acesso às TICs para as PNEEs que passam longos períodos hospitalizadas, em isolamentos, afastando e impossibilitando o convívio com outras crianças. O período de internamento hospitalar, o tratamento intensivo e o isolamento do convívio com outras pessoas, tornam necessárias e significativas a realização de atividades sócio-educativas. Dentre as atividades que podem ser desenvolvidas, destaca-se a contação de histórias e o acesso aos materiais de leitura junto ao leito hospitalar, tendo como suporte as TICs, as quais podem se fazer presentes nesse ambiente, não afastando as crianças do mundo real, do exercício da leitura, da escrita, da produção textual e da interação desse processo com outras crianças PNEEs ou não, próximas ou distantes geograficamente.

O Hospital de Clínicas de Porto Alegre (HCPA) desde 1979 oferece aos pacientes internados, espaços e atividades lúdico-terapêuticas com objetivo de amenizar os efeitos da hospitalização, favorecendo a adaptação à rotina hospitalar e possibilitando a melhoria da qualidade de vida. Além dos atendimentos em salas especiais, quartos e áreas restritas, os pacientes recebem acompanhamento recreativo alicerçado nos princípios da criatividade, autonomia e cooperação, interligando educação e saúde.

A realização de projetos de pesquisa no âmbito do HCPA passa por um processo de análise e aprovação junto ao Grupo de Pesquisa e Pós-Graduação (GPPG), formado pelos Serviços de Consultorias e pelas Comissões Científica e a de Pesquisa e Ética em Saúde para avaliarem e acompanharem o andamento dos projetos de pesquisa. Dentre os Projetos avaliados e aprovados no início de 2005, encontra-se o Projeto de Pesquisa "A Interação Através da Informática na Educação com Crianças com Fibrose Cística e a Inclusão Social e Digital Através do Uso da Leitura e da Escrita: um estudo de caso nos isolamentos da Pediatria do HCPA", sob a coordenação dos autores deste 
trabalho. A aprovação do Projeto propiciou a criação de um Núcleo da RedespecialBrasil (RIBIE) no HCPA, com o apoio tecnológico para a execução das ações previstas.

Este trabalho apresenta a realização de uma experiência com atividades utilizando as TICs e o uso de ferramentas eletrônicas, desenvolvida na área de Informática na Educação, tendo como sujeitos duas pacientes hospitalizadas na Pediatria do HCPA, internadas em quartos restritos, recebendo o tratamento médico em isolamento total. A experiência evidencia aspectos do foco do Projeto aprovado no GPPG do HCPA como proposta de interação dos doentes crônicos em seu contexto sociocultural. Dentre os objetivos propostos para a realização da atividade, podem-se destacar: verificar a possibilidade de interação, de inclusão social e digital de pacientes com fibrose cística e outras doenças crônicas, hospitalizadas em isolamentos; propiciar a comunicação, através da expressão e da percepção, utilizando a linguagem oral e a linguagem escrita, tendo como mediação e ferramenta tecnológica o computador; possibilitar o acesso e a adaptação dos recursos tecnológicos para os participantes da atividade; estabelecer, através da videoconferência, uma relação com o mundo, transformando a vida e propiciando a inclusão social e digital; minimizar o sentimento de isolamento, de solidão e de exclusão, estimulando a segurança em si mesmo, a autoestima e a integração através da interação, do compartilhamento e da comunicação com o outro; fortalecer o sentimento de solidariedade e respeito mútuo, baseado nos resultados da atividade proposta.

\section{EXPERIENCIANDO A INTERAÇÃO, ATRAVÉS DAS TICS, NA PEDIATRIA DO HCPA-RS}

Os pacientes com fibrose cística e os pacientes transplantados são considerados PNEEs, por se afastarem periodicamente da escola para tratamento hospitalar, interrompendo o convívio com os colegas e professores e o ritmo da sala de aula. A fibrose cística exige tratamento contínuo e ininterrupto com longos períodos de baixas hospitalares onde os pacientes ficam internados em quartos isolados do convívio com outras crianças, caracterizando-se como uma doença genética, progressiva e incurável. O HCPA se constitui em um centro de referência no Brasil, especializado no atendimento e acompanhamento dos pacientes fibrocísticos e, o Rio Grande do Sul, é um dos estados com maior incidência da doença no panorama brasileiro. Por outro lado, na Pediatria do HCPA, é significativo o número de pacientes transplantados que ficam internados em quartos restritos.

A atividade que experienciou a interação, através do uso das TICs, mediada por computador, contou com duas participantes (uma com fibrose cística e a segunda, transplantada), internadas em quartos restritos, na faixa etária entre 10 e 12 anos, denominadas Paciente 1 e Paciente 2, para preservar as suas identidades. As duas pacientes estavam internadas em quartos vizinhos, sem nunca terem se comunicado.

Foram instalados dois computadores com estabilizadores, microfones, câmera web, cabo de rede de $20 \mathrm{~m}$ ligando os dois quartos. No equipamento da Paciente 1 , que nunca tinha usado um computador, havia uma câmera que possibilitava à Paciente 2 acompanhar, através da imagem, todos os movimentos no decorrer da videoconferência. As duas utilizaram a linguagem oral (através do microfone) e a linguagem escrita (através do computador).

Os recursos utilizados foram o quadro de comunicação, o bate-papo e a conversação oral. No quadro de comunicação, as pacientes interagiram, de forma colaborativa, através de desenhos e formas gráficas, apresentando as suas habilidades, idéias e criatividade. No bate-papo foi utilizado o Chat, como recurso de troca de 
mensagens escritas através de texto, onde expressaram curiosidades uma sobre a outra, trocaram idéias e impressões realizando plenamente o processo de comunicação. Embora a Paciente 1 estivesse digitando pela primeira vez em um teclado a Paciente 2 decodificava / percebia a mensagem recebida.

A Paciente 1 mostrava-se bem mais tímida, mas bastante interessada, motivada pela primeira experiência em utilizar os recursos oferecidos pelas ferramentas computacionais. A Paciente 2, mostrava-se muito entusiasmada para iniciar as atividades, perguntando, durante todo o tempo de instalação dos equipamentos, sobre as atividades que desenvolveria, quais ferramentas seriam utilizadas, como era a Paciente 1, demonstrando muita disponibilidade para a experienciação.

No desenvolvimento da atividade, as coordenadoras não interferiram "ensinando" como realizar os desafios, mas propuseram algumas atividades iniciais, como o uso do quadro de comunicação. O papel das coordenadoras foi de incentivar o uso das ferramentas, não intervindo, mas mediando, no sentido de estimular a realização das atividades e da interação e a construção do conhecimento pelo próprio sujeito. No momento que foi disponibilizado o quadro de comunicação, as duas Pacientes imediatamente iniciaram o uso do "mouse" registrando os primeiros traços que lembravam figuras geométricas coloridas (Fig.1). Em seguida partiram para um esboço de figura humana, iniciada pela Paciente1 que prontamente contou com a participação da Paciente 2, interagindo nos detalhes a serem acrescentados (Fig.1).

O "quebra-gelo" inicial entre as duas, aconteceu através do uso do microfone, estabelecendo um diálogo através da "linguagem falada social". Segundo Tijiboy ; Santarosa ; Tarouco (2002, p. 140) a linguagem falada social se caracteriza por "manifestações em que a fala desempenha a função social. [...] tem a finalidade de estabelecer uma comunicação com outras pessoas implicando uma comunicação bilateral entre os interlocutores. Refere-se também a situações em que o sujeito mostra comportamento de empatia, de interação cordial, levando em consideração o outro."

A Paciente 2 perguntou se era possível também escrever no quadro do desenho. Diante da possibilidade confirmada por uma das coordenadoras, imediatamente registrou que o desenho estava bonito. Em resposta, a Paciente 1 escreveu: "Obrigada. Vamos fazer outro desenho?" A Paciente 2 solicitou que a Paciente 1 desenhasse para ela. Prontamente esta atendeu ao pedido, desenhando várias "bolas coloridas" (conforme a Paciente 2 denominou), sempre observando as reações da Paciente 1 através da câmera instalada em sua máquina. Ao final, a Paciente 2 contou as figuras e registrou no quadro : "26 bolas".

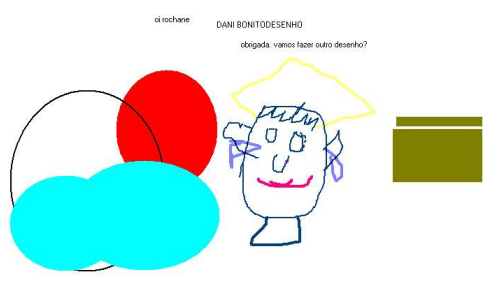

Figura 1: Desenho compartilhado

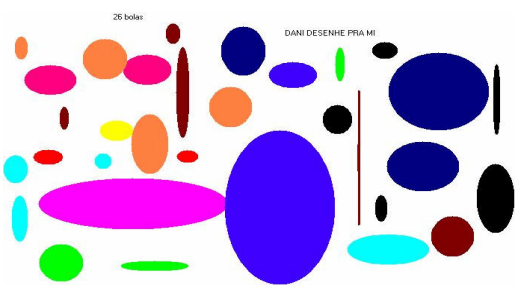

Figura 2: Desenho da Paciente 1 ("bolas")

Vygotsky (1996, p.213) afirma que "para entender corretamente o significado dos momentos concretos da fantasia do adolescente temos de levar em conta a conexão existente entre a imaginação do adolescente e o jogo da criança". Tijiboy ; Santarosa ; Tarouco (2002, p. 140) caracterizam a imaginação como a "capacidade propor ou fazer algo diferente do comum. Pode envolver manifestações verbais, escritas, gráficas". Aqui, a imaginação envolveu as três manifestações: verbais, através do uso do 
microfone, escritas utilizando o quadro de comunicação e o bate papo e gráficas através dos traços desenhados.(Quadro 1 e Figuras 1 e 2).A imaginação "refere-se à construção de novas combinações e formas a partir de impressões acumuladas anteriormente." Para as autoras, a formulação de questões que vão além de sua experiência imediata podem ser manifestações de "novas formas e combinações que o sujeito apresenta na sua ação."

Observou-se que não houve nenhum momento de constrangimento, apesar da timidez da Paciente 1 por não saber digitar. Ao iniciar a atividade, a Paciente 1 foi "selecionando" tecla por tecla para expressar as palavras necessárias às respostas das perguntas de iniciativa da Paciente 2. O bate-papo teve a duração de aproximadamente meia hora, onde a escrita foi mais dificultada pela falta de habilidade com a ferramenta, e com a morosidade para digitar as palavras, verificado especialmente na Paciente 1. Pode--se perceber (Fig.3) que a Paciente 1 não deu espaçamento entre as palavras, mas a Paciente 2 em momento algum fez qualquer comentário, lendo corretamente as respostas. Frawley (2000) afirma que o contexto tem relação com o pensamento ao concentrar a atenção dos participantes. Os efeitos da linguagem passam para o primeiro plano ao acompanhar explicitamente os aspectos do entorno informacional. "A linguagem concentra a atenção e codifica a perspectiva através de dispositivos que funcionam expressamente para eliminar a lacuna existente entre contexto e código".(FRAWLEY, 2000, p.109). O bate-papo iniciou com a participação ativa da Paciente 2 sempre tomando a iniciativa das perguntas e tão logo recebia a resposta já enviava outra pergunta formulada por ela.

No período da manhã, a Paciente 2 havia realizado processo cirúrgico para substituição de botton gástrico no abdômen. Ao final das três perguntas iniciais, a Paciente 2 recebeu a visita do médico, ingeriu medicamentos ministrados pela auxiliar de enfermagem, atendeu ao celular e, em todas essas intervenções procurou sempre se "desvencilhar" rapidamente para continuar no bate-papo enquanto a Paciente 1 a aguardava tranqüilamente. As duas pacientes foram descobrindo as possibilidades e compartilharam as ações de comum acordo e com prontidão para a realização das atividades propostas por elas, radiantes por vencer qualquer dificuldade que pudesse se apresentar justificando a afirmativa de Vygotsky (1996, p.222): "as pessoas e as máquinas são compatíveis".

A atividade foi encerrada, quando a Paciente 2 percebeu, através da câmera que a Paciente 1 estava cansada e o jantar já estava chegando ao quarto. (Fig. 3).

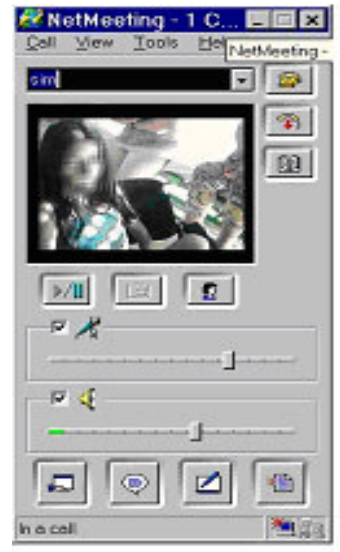

Figura 3: Paciente 1 visualizada pela Paciente 2 através do NetMeeting

Foi uma tarde prazerosa de interação e compartilhamento para as duas pacientes, que se envolveram ativamente em todos os momentos da experiência, envolvendo também, indiretamente, a mãe da Paciente 2, que ao final da atividade agradeceu 
emocionada o que havia sido proporcionado, durante a tarde, para sua filha. A acompanhante da Paciente 1, também agradeceu, uma vez que a sua mãe não se encontrava presente no momento, mas que havia autorizado a sua participação.

\section{A INTERAÇÃO MEDIADA POR COMPUTADOR ATRAVÉS DO BATE-PAPO}

Vygotsky já afirmava que o acesso ao simbólico acontece através da interação entre sujeitos. A interação se caracteriza como uma relação colaborativa e participativa não estando caracterizada somente nos resultados ou metas alcançadas para a aquisição do conhecimento mas principalmente nas potencialidades a serem exploradas entre homem X máquina. Steuer ${ }^{5}(1991)$ apud Primo (2000, p.68) define a interação como "a extensão em que os usuários podem participar modificando a forma e o conteúdo do ambiente mediado em tempo real." Para Steuer (1991), a interação significa "uma variável direcionada pelo estímulo e determinada pela estrutura tecnológica do meio". O uso das TICs propicia a interação e a inclusão social e digital quando se acredita que é possível transformar, construir, permitindo que o paciente seja agente ativo de um processo de construção e de aprendizagem.

A mediação entre sujeito e objeto é feita, não apenas pelos recursos projetados e disponíveis dentro do mundo (instrumentos) mas também pela interação com outros sujeitos que constituem um contexto semiótico repleto de novas significações e influenciando o processo de construção do próprio pensamento e da tomada de consciência. (PASSERINO; SANTAROSA, 2003).

Vygotsky (1984) demonstrou que ao experimento cabia o importante papel de desvendar os processos que estão encobertos pelo comportamento habitual. Para ele as crianças podem imitar uma variedade de ações que vai muito além dos limites de suas próprias capacidades. $\mathrm{O}$ autor defende que a escrita desempenha um papel fundamental no desenvolvimento cultural da criança. Os sinais escritos constituem símbolos de primeira ordem, denotando diretamente objetos ou ações em que a criança terá de evoluir no sentido do simbolismo de segunda ordem que compreende a criação de sinais escritos representativos dos símbolos falados das palavras. Para isso, a criança realiza uma descoberta básica: a de que se pode desenhar além das coisas, também a fala. Foi essa descoberta que levou a humanidade ao brilhante método da escrita por letras, frases $\mathrm{e}$, as crianças, à escrita literal. "Enquanto símbolos de segunda ordem, os símbolos escritos funcionam como designações dos símbolos verbais".(VYGOTSKY,1984).

Hoje, sabe-se que a aprendizagem acontece de forma mais significativa, quando melhores interações possam ocorrer e que as experiências de vida de cada aprendiz contribuem para o crescimento do saber social. Sabe-se, também, que se aprende com o prazer, com o afeto e o respeito às particularidades de cada pessoa envolvida. A aprendizagem, no contexto atual, é vista como dinâmica: acontece em momentos particulares e respeita estilos próprios. Isso foi possível verificar no decorrer do batepapo realizado pela Paciente 1 e Paciente 2. (Quadro ${ }^{\circ} 1$ ).

\begin{tabular}{|l||l|l|l|}
\hline Paciente 1 & $12 / 1 / 2005$ & $18: 08: 07$ & O I \\
\hline Paciente 2 & $12 / 1 / 2005$ & $18: 09: 02$ & voce esta gostando de fazer essa atividad \\
\hline \hline
\end{tabular} $\begin{aligned} & { }^{5} \begin{array}{l}\text { STEUER, Jonathan. Definig Virtual Reality: dimensions determining telepresence. In: Journal of Comunication, v.4, } \\
\text { n...42,1991, p.72-93. }\end{array} \\
& 6 \_ \text {V. } 3 \mathrm{~N}^{\circ} 1 \text {, Maio, } 2005\end{aligned}$




\begin{tabular}{|c|c|c|c|}
\hline & & & Novas Tecnologias na Educação \\
\hline Paciente 1 & $12 / 1 / 2005$ & 18:10:01 & SINESTOUGOSTANDO \\
\hline Paciente 2 & $12 / 1 / 2005$ & $18: 11: 55$ & voce tem muitos amigos \\
\hline Paciente 1 & $12 / 1 / 2005$ & $18: 13: 23$ & MAISOMENOS \\
\hline Paciente 2 & $12 / 1 / 2005$ & $18: 14: 37$ & voce estuda \\
\hline Paciente 1 & $12 / 1 / 2005$ & 18:15:31 & SIN \\
\hline Paciente 1 & $12 / 1 / 2005$ & 18:16:12 & IVOCE \\
\hline Paciente 2 & $12 / 1 / 2005$ & $18: 22: 32$ & Sim \\
\hline Paciente 2 & $12 / 1 / 2005$ & $18: 23: 59$ & que serie voce esta \\
\hline Paciente 1 & $12 / 1 / 2005$ & $18: 24: 15$ & VOCEGOSTADEISTORIA \\
\hline Paciente 2 & $12 / 1 / 2005$ & $18: 24: 41$ & muito \\
\hline Paciente 1 & $12 / 1 / 2005$ & $18: 25: 23$ & EUESTOUNATERCERA \\
\hline Paciente 2 & $12 / 1 / 2005$ & $18: 25: 54$ & estou na quintaserie \\
\hline Paciente 1 & $12 / 1 / 2005$ & 18:27:01 & VOCETENNAMORADO \\
\hline Paciente 2 & $12 / 1 / 2005$ & $18: 27: 44$ & mais ou menos \\
\hline Paciente 2 & $12 / 1 / 2005$ & 18:28:03 & e voce \\
\hline Paciente 1 & $12 / 1 / 2005$ & $18: 28: 30$ & NAO \\
\hline Paciente 2 & $12 / 1 / 2005$ & $18: 29: 17$ & de qual cantorvoce gosta \\
\hline Paciente 1 & $12 / 1 / 2005$ & 18:30:13 & FILIPEDILON \\
\hline Paciente 2 & $12 / 1 / 2005$ & 18:31:00 & eu tambem amo ele \\
\hline Paciente 1 & $12 / 1 / 2005$ & $18: 31: 49$ & VOCETENFOTODELE \\
\hline Paciente 2 & $12 / 1 / 2005$ & $18: 32: 13$ & e a eliane que esta te dizendo isso \\
\hline Paciente 2 & $12 / 1 / 2005$ & $18: 32: 55$ & eu tenho mutas ate autografos dele \\
\hline Paciente 2 & $12 / 1 / 2005$ & $18: 35: 20$ & que programa voce gosta de assistir \\
\hline Paciente 2 & $12 / 1 / 2005$ & $18: 37: 21$ & voce esta cansada \\
\hline Paciente 1 & $12 / 1 / 2005$ & 18:37:53 & SIN \\
\hline Paciente 2 & $12 / 1 / 2005$ & 18:38:56 & um beijo e outro dia a gente conversa \\
\hline Paciente 1 & $12 / 1 / 2005$ & $18: 41: 38$ & UMBEIJAO \\
\hline
\end{tabular}

\section{Quadro no 1: Bate-Papo legal no Clínicas}

Analisando os indicadores dos processos de desenvolvimento publicados por Tijiboy ; Santarosa ; Tarouco (2002, p. 140), verifica-se que ocorreu a "auto-reflexão / autoconsciência durante o bate papo, quando as duas pacientes mostraram a capacidade de "lidar com sua própria vida interior, de analisar seu mundo interior e de avaliar suas qualidades intrínsecas". Caracteriza-se também como a capacidade"de se relacionar com suas próprias características de personalidade, seus próprios traços de caráter.[...] Envolve os processos de percepção das próprias qualidades e limitações, a auto-análise e auto-avaliação."Isso ocorreu algumas vezes durante a interação entre as duas pacientes, exemplificando-se quando a Paciente 2 perguntou : " você esta gostando de fazer essa atividade" ao que a Paciente 2 respondeu afirmativamente. A percepção também se manifestou claramente quando a Paciente 2 "percebeu", observando a expressão corporal da Paciente 1, através da câmera, e a maior demora em responder através da digitação registrando: "voce esta cansada" ao que a Paciente 1 respondeu "SIN".

A postura de cooperativa também foi observada através das atitudes e aspectos manifestados pelas Paciente 1 e Paciente 2 onde houve o respeito à individualidade e à V. $3 \mathrm{~N}^{\mathrm{o}}$ 1, Maio, 2005 
diversidade, demonstrando atitudes de tolerância, de convívio amigável, cordial e de empatia, evidenciando "relações heterárquicas, onde existem trocas, colaborações e momentos de reflexão". Quando a Paciente 2 perguntou "de qual cantor você gosta" e a Paciente 1 respondeu o mesmo que a Paciente 2 "ama", a mesma voltou-se para uma das coordenadoras e comentou que não acredita que as duas "amassem" o mesmo cantor, que só podia a outra coordenadora estar influenciando na resposta que recebera e, em seguida, registrou: "e a eliane que esta te dizendo isso". Mas ao constatar que a Paciente 1 não possuía fotos do cantor, demonstrou imediatamente uma atitude amigável de empatia e de cordialidade, falando ao microfone, que a presentearia com uma de suas fotos do cantor.

Ao encerrar as atividades as duas enviaram "beijo" e "UMBEIJAO", em uma demonstração de afeto nascido numa tarde de verão, no isolamento de um quarto restrito de hospital, onde a fronteira tríplice entre informática na educação, inclusão digital e inclusão social propiciou momentos de afeto, de interação, de lenitivo, de terapêutica e de auto-estima para quem enfrenta a solidão e o tratamento de uma doença crônica.

Essa atividade permitiu verificar que o acesso e a adaptação de recursos tecnológicos em ambientes como os isolamentos de hospitais, podem propiciar a comunicação, a expressão, a interação e o compartilhamento entre pacientes hospitalizados. É possível minimizar o sentimento de isolamento e de medo, característicos do ambiente hospitalar, fortalecendo o sentimento de solidariedade, a auto-estima e o compartilhamento com o outro.

Vygotsky enfatiza que a inteligência humana provém da "nossa sociedade ou cultura" e que ocorre através da interação com o ambiente social, explicada através da teoria sociocultural, baseada na intersubjetividade e na ZDP. A compreensão da AAMC é portanto, a sociocultural. $\mathrm{O}$ aprendizado precede o desenvolvimento, quando a criança, através de sua experiência cotidiana, no convívio com as pessoas de seu meio, de sua cultura, forma e utiliza os conceitos espontâneos sem estar consciente deles. No período de escolaridade, com a aquisição dos conceitos científicos, ela adquire a capacidade de defini-los por meio de palavras e de operar com os mesmos.

A auto-estima também ficou evidenciada, através do sentimento de satisfação manifestado pelas duas pacientes, com relação a si mesmas e com relação ao seu desempenho na interação com as ferramentas, com o ambiente e com "o outro". O sentimento de auto-estima poderá minimizar o sentimento de solidão e de exclusão. A descoberta por parte dos sujeitos desta atividade, auxiliou-os "a se perceberem como capazes não só de utilizar com destreza" as TICs "mas também de continuarem a aprender e a se desenvolverem pelo resto de suas vidas." (TIJIBOY ; SANTAROSA ; TAROUCO, 2002, p.150).

\section{CONSIDERAÇÕES FINAIS}

As PNEEs sofrem preconceitos e exclusão pela própria sociedade que se preocupa em "incluí-los". Eles apresentam diferenças e não limitações. Os doentes crônicos, pacientes com fibrose cística, internados nos isolamentos do HCPA sofrem com o afastamento do seu ambiente da família, dos amigos, dos colegas de escola, entre outros. O processo da doença e do tratamento exige muita dedicação, tenacidade e perseverança dos pacientes e dos familiares. Mesmo assim, os sonhos e as fantasias permeiam o seu imaginário, realimentado através da contação de histórias. Este Projeto, através da percepção e da identificação com os personagens das histórias contadas, pretende recuperar o afeto, o prazer, a sensibilidade, a criatividade, a magia das histórias amenizando a situação de confinamento e de dor. A Informática na Educação é a ponte que estabelece um vínculo entre os sujeitos, ao mesmo tempo em uma situação em que 
a criança está "afastada do mundo" permite "trazer o mundo" para o alcance da criança, pois "quando a gente se comunica, constrói mundos". (MARASCHIN, 2001).

Todos os envolvidos no Projeto serão sensibilizados não somente pelas ações mas pelos resultados que eles podem apresentar. A relevância desse Projeto é a oportunidade de o sujeito se tornar ativo, participante, criativo, retomando "as rédeas de sua vida" ao invés de ser passivo pela situação e pela condição da doença crônica. $O$ mais importante é a conscientização de que ele pode superar os limites que lhes são impostos, só não foram oferecidas oportunidades.

No ambiente hospitalar o paciente não tem autonomia, ficando à mercê das determinações e decisões que o tratamento exige. Através das atividades e experimentações desenvolvidas neste Projeto, será oportunizado o exercício da autonomia propiciando a interação entre sujeitos e a inclusão social e digital através do uso da leitura e da escrita em ambientes informáticos, como vivência educativa, terapêutica e social.

Este Projeto de Pesquisa na área de Informática na Educação é pioneiro no âmbito de hospitais públicos e de pacientes crônicos, caracterizando-se com a possibilidade inúmera outras opções e desdobramentos propiciando novas investigações e resultados tendo como sujeitos doentes crônicos com fibrose cística, oportunizando construir pontes e elos entre a criança hospitalizada internada em quartos restritos e as ferramentas telemáticas como meio para ai interação com outras criança próximas e / ou distantes, observando que o computador é um instrumento de ligação, de interação, mas sobretudo de afeto entre as pessoas..

Através do uso da escrita e das ferramentas eletrônicas, pretende-se estabelecer uma relação com o mundo, transformando a vida e oportunizando a inclusão social e digital. Pretende-se também a busca da mudança de paradigma nos ambientes de isolamentos hospitalares, através da AAMC, como estratégia educativa onde as TIC's estão presentes como mediadoras do processo de inclusão social e digital e de produção textual, como prática educativa, terapêutica e social. Através da Informática na Educação, é possível transformar, construir, a partir desse imaginário, traduzindo através de textos e imagens, permitindo que a criança seja agente ativa de um processo de construção e aprendizagem. . . seja feliz!

\section{REFERÊNCIAS}

ESTABEL, Lizandra B.; MORO, Eliane. Ambiente de aprendizagem mediado por computador e os portadores de necessidades educacionais com limitação visual: abordagens de cooperação e colaboração. In: ABED: Congresso Internacional de Educação a Distância,10,2003, Porto Alegre, PUCRS, 2003. Disponível em: http://www.abed.org.br/congresso2003/docs/anais/TC07.htm. Acesso: 23 mar. 2005.

FRAWLEY, William. Vygotsky e a Ciência Cognitiva: linguagem e integração das mentes social e computacional. Trad. Marcos A.G. Domingues. Porto Alegre : Artes Médicas, 2000.

HODSON, M.E. ; GUEDES, D. M. Cystic Fibrosis. Chapman:H. Medical, 1995. MARASCHIN, Cleci. Disponível em: <www.pgie.ufrgs.br/ elianem/eco_cognitiva.htm>. Acesso em: 20 dez.2004.

PASSERINO, Liliana; SANTAROSA, Lucila M. C. Uma Visão Sócio-histórica da Interação dentro de Ambientes Computacionais. Disponível em: 
http://www.c5.cl/ieinvestiga/actas/ribie2000/papers/200/index.htm. Acesso:16 jan. 2003.

PRIMO, Alex F. T. Uma Análise Sistêmica da Interação Mediada por Computador. In: Informática na Educação: teoria e prática. Porto Alegre, UFRGS / PGIE, v.3, n.1, p.73-84, set.2000.

RATNER, C. A Psicologia Sócio-Histórica de Vygotsky : aplicações contemporâneas. Porto Alegre : Artes Médicas, 1995.

TIJIBOY, Ana V.; SANTAROSA, Lucila M.C.; TAROUCO, Liane. A Apropriação das Tecnologias de Informação e Comunicação por Pessoas com Paralisia Cerebral. In: Informática na educação: teoria e prática. Porto Alegre, Revista do Curso de Pós-Graduação em Informática na Educação, v.5, n.2, nov.de 2002, p. 131152.

VYGOTSKY, L. S. A Formação Social da Mente. São Paulo : Martins Fontes, 1984.

VYGOTSKY, L. S. Pensamento e Linguagem. São Paulo : Martins Fontes, 1987. 